\title{
AN EIGHTEENTH-CENTURY CASE HISTORY: CARLISLE SPEDDING 1738
}

by

\author{
J. V. BECKETT*
}

\begin{abstract}
CARLISLE SPEDDING was principal colliery steward to the Lowther family from about 1730 until his death in 1755 . He was responsible for their mining interests, centred on Whitehaven in West Cumberland. His work frequently took him underground, where he was exposed to the inflammable gases found in mines. Ventilation methods were still primitive, and as a result of his exposure Spedding was frequently ill. A case history of his indisposition in 1738 has survived. This was the work of the Leyden-trained chemist and physician, Dr. William Brownrigg, and it reveals some of the symptoms encountered and remedies proposed for one particularly severe bout of illness.
\end{abstract}

The document printed below describes an illness suffered in 1738 by Carlisle Spedding (1695-1755), principal colliery engineer and steward to Sir James Lowther of Whitehaven (1673-1755). Spedding was an inventor and engineer of considerable repute in the eighteenth century, but as the first paragraph of the document makes clear, he suffered acutely from the effects of over-exposure to the contaminated atmosphere found in coal mines: as his brother John expressed it in 1734 "all his illnesses (in which he is held pretty much alike) seem to proceed from the effects of the damp air underground". The term "damp air", or the more common form "firedamp", was loosely applied to the inflammable gases found in mines, which are usually methane, but sometimes hydrogen sulphate. ${ }^{2}$ As colliery steward, Spedding was often underground; indeed, he clearly believed that this was a necessary part of his job, as John Spedding revealed in a letter to Sir James Lowther following an explosion in 1737:

I have told him over and over that you do not expect he should run such risks ... and that he may get three or four of the knowingest workmen to go about such sort of things and act by his directions and that all the workmen knowing he has never spared exposing himself nor would do it but only that the damp air has so bad an effect upon his health, would be willing he should be excused from it, and would

* J. V. Beckett, B.A., Ph.D., F.R.Hist.S., Department of History, University of Nottingham, University Park, Nottingham NG7 2RD.

\footnotetext{
${ }^{1}$ Carlisle Record Office, D/Lons/W John Spedding to Sir James Lowther, 8 November 1734 (hereafter Spedding to Lowther, and vice versa).

'It should be distinguished from the non-inflammable but equally dangerous "choke-damp" (carbon dioxide).
} 


\section{J. V. Beckett}

be directed by those he set over them to head them upon such occasions. He says if he had not been there and were not always with them upon such occasions they are so miskillful or foolhardy that many more of them would have been destroyed, and he cannot keep back, though he know it is destruction to his health to be long in the bad air. ${ }^{3}$

Spedding was greatly concerned with efforts to improve mine ventilation, and to this end he teamed up in 1737 with the author of the document printed below, Dr. William Brownrigg (1712-1800). Educated at Leyden, Brownrigg returned to his native West Cumberland in 1737 , and soon became the most notable physician in the area. He had a wide range of interests, among them the problems of mine ventilation, and in 1743, a laboratory was built, into which "fire-damp" was piped for him to examine. As a physician, Brownrigg kept a case-book for the years 1737 to 1742 which has survived, and which includes this account of Spedding's health."

The particular events which underpinned the following document began in the summer of 1737 , at roughly the same time as Brownrigg returned to Whitehaven. In August that year, an explosion in one of the mines killed twenty-three workmen. Spedding "saved the life of one man with great hazard of his own but all the rest perished". The exertions left him "very much out of order", and Lowther wrote from London to ask that Brownrigg should be requested to draw up a state of his health, which could then be laid before Sir Hans Sloane (1660-1753). ${ }^{6}$ Sloane, one of the foremost physicians of his day, was a personal friend of Lowther. Brownrigg's casebook shows that he was quite used to the common eighteenth-century practice of diagnosis by letter; indeed, he was to draw up an account of Sir James Lowther's own illness in the summer of 1742 in order to seek Sloane's advice. ${ }^{7}$ John Spedding reported back to Lowther that "Dr Brownrigg has been desired to state the nature of this disorder, but he is not yet prepared for it". Lowther responded by suggesting that Brownrigg be offered a fee for his services, but in fact Spedding recovered before anything more was done.9 However, as the following account reveals, Spedding remained slightly unwell over the following months, and in January 1738, he was again taken ill. This time, Brownrigg kept a full history of the case, although whether for the purpose of informing Sloane is not known.

$1738 \mathrm{Mr}$ Carlyle Spedding ${ }^{10}$

A man of forty, robust, of intelligent appearance, sanguine temperament, from boyhood employed at the coalmines and director of works, from the stifling exhalations whereof he

${ }^{3}$ Spedding to Lowther, 10 August 1737.

‘ Carlisle Library, Brownrigg's Case Book, 1737-42. On Brownrigg see: J. V. Beckett, 'Dr. William Brownrigg, F.R.S.: physician, chemist and country gentleman', Notes Rec. R. Soc. Lond., 1977, 31: 255-271; J. Russell-Wood, 'A biographical note on William Brownrigg, M.D., F.R.S. (1711-1800)', Ann. Sci., 1950, 6: 186-196; idem, 'The scientific work of William Brownrigg, M.D., F.R.S. (1711-1800)', ibid., 1950, 6: 436-444; 1951, 7: 77-94, 199-206.

${ }^{3}$ Spedding to Lowther, 5 August 1737.

- Spedding to Lowther, 10 August 1737, Lowther to Spedding 16 August 1737.

$7 \mathrm{~J}$. V. Beckett, 'Illness and amputation in the eighteenth century: the case of Sir James Lowther (1673-1755)', Med. Hist.; 1980, 24: 88-92.

- Spedding to Lowther, 21 August 1737.

- Lowther to Spedding, 27 August 1737.

${ }^{10}$ Carlisle Library, Case Book. This is a bound volume of 240 pages, written mostly in Latin and including, apart from medical cases, discourses on other subjects, including two pages on the weather at Whitehaven. I should like to thank Dr. Audrey Eccles for translating the present document. 


\section{An eighteenth-century case history}

had been affected by serious and persistent ailments. Indeed, on one occasion, prostrated by these lethal gases he was brought to the verge of death from consumption; moreover in the summer last past he entered mines full of stifling gases, his strength scarcely sufficed to see the light of day again, from that time he complained of headache and frequent throbbing of the cephalic arteries, and when he concentrated of failure of internal senses, his respiration also on increased effort became difficult and laboured and the chest cavity as it were constricted, his respiration also affected in the same manner by the smallest drink of spirituous liquors; if he raised his head and face or leaned forwards he always became giddy, to relieve this affliction I had prescribed pills, but with only moderate success.

Jan 2. But on Jan 2, when he walked in the tunnels the distance of a mile, he came at length to a place where the water was obstructed by rubbish and he passed this place, casting himself, hot and covered with sweat, up to the chest in the water, nor in that freezing temperature did he change his soaking clothes for an hour; he was affected for two weeks after with intermittent pains, weariness and other symptoms of having caught cold.

15. On the $15^{\text {th }}$ in the evening he was seized by a chill and shivering which bereft him of heat. On the next morning I found the following symptoms of illness.

Swifter pulse, little natural heat, feverish, respiration easy, cough with splitting headache, continual throbbing of the cephalic arteries, swallowing languid, white tongue, severe shooting pains especially in the legs, shoulders and backbone. Having first let some blood he was less inflamed.

17. He slept peacefully at night, swallowed mostly with discomfort, remaining symptoms as yesterday; in the evening the headache was worse, therefore I allowed the application of two leeches to the temples, then at a late hour when he had a drink of hot milk with canary the cough instantly increased and the difficulty of breathing became very great with a rattling noise "a Crowing"; he struggled to expand his chest with very great effort, but for two hours he could scarcely fill his lungs even a little, so much so that his face became almost black with stagnant blood and the eyes remained fixed, staring intently. At length the lungs expanded and the paroxysm receded, he was quite cheerful all the next evening and all the symptoms somewhat abated. [Prescription for apozeme and gargarism in margin, also note about letting of 10 ounces of blood from the arm, application of two leeches to the temples, and a blister to the shaven head.]

18. The feverish heat and shooting pains and headache somewhat diminished, but the difficulty in swallowing increased and when the throat is dry a pricking pain arises about the larynx and soft palate, which parts are somewhat inflamed. Nevertheless the appetite remains good. Milk sweetened with honey and sugar is taken in large quantities. At night he sweated copiously.

19. He slept profoundly at night but at intervals the throat became dry, on one occasion for a moment of time he was attacked by difficulty of breathing. In the morning the inflammation of the throat worsened so much that the jugular vein was opened and 10 ounces of blood taken, the first measure [of blood] was slightly inflamed. In the evening the inflamed parts were dry and he was unable to swallow so that the venesection was repeated in the arm and 12 ozs of blood taken; no sign of inflammation appeared in the blood. After the bleeding he swallowed, I examined the throat, the uvula and throat are somewhat red and as it were inflamed.

20. Sound sleep at night. In the morning no fever but the throat inflammation persists. He took a potion which gave a vomit and five stools as he lay in bed, the pain in the throat subsided, he lay for the whole day on the bed, in the evening the pain in the throat increased somewhat but he could swallow without great discomfort. 


\section{J. V. Beckett}

21. Signs as yesterday: a slight cough coming on.

22. The same signs; he took half of the prescribed potion without vomiting, but since he was unable to take the other part on account of nausea I prescribed 6 drams Crem. to be taken at thrice, which gave seven stools. The pain in the throat was pretty well sedated.

24. Since the belly had not been moved for two days and he did not wish to repeat the purgative potion I prescribed an enema which gave two stools. He swallowed mostly with ease, he sat up almost the whole day without much discomfort. Profuse sweating all night.

25. I prescribed a purgative potion which gave five stools. The tongue appeared somewhat furred and dark. There was a troublesome cough and a sort of heaviness of the chest and pain in the head and from time to time ringing in the left temple.

26. On inspecting the throat the uvula appeared normal, but on the back part of the throat above the larynx there appeared many broad white spots after the likeness of lard, or of the pustules of thrush. Nevertheless the pain and difficulty of swallowing diminished. These little ulcers of the throat gradually vanished, but the wrists, knees and ankles remained affected by rheumatic pains until the end of the following April, these joints were somewhat weak, the wrists and ankles were often swollen, but all other symptoms of disease disappeared almost, nor did he feel any further effects of the head and chest, in so much that he enjoyed better health than before the onset of the disease.

Spedding recovered and was soon back in the mines, but he continued to suffer from the effects of too great exposure to the poisonous atmosphere, and, during the $1750 \mathrm{~s}$, from an eye infection also contracted underground. Perhaps not surprisingly, he died in the mines; killed in an explosion on 8 August 1755. 